\title{
FORECAST STRUCTURE DEVELOPMENT FOR MODELLING THE SOUTHERN BRAZILIAN CONTINENTAL SHELF HYDRODYNAMIC
}

\author{
C. E. Stringari ${ }^{\mathrm{a}}$, \\ E. P. Kirinus ${ }^{b}$, \\ J. Costi ${ }^{\mathrm{c}}$, \\ P. H. Oleinik ${ }^{\mathrm{b}}$, \\ and W. C. Marques ${ }^{c}$ \\ ${ }^{a}$ Department of Earth Sciences \\ University of Newcastle \\ University Drive, Callaghan \\ NSW 2308, Australia \\ ${ }^{\mathrm{b}}$ Escola de Engenharia \\ Universidade Federal do Rio Grande \\ Campus Carreiros. Av. Itália s/n Km 8 \\ CEP 96201-900. Rio Grande, RS, Brasil \\ ${ }^{\mathrm{c} I n t i t u t o ~ d e ~ M a t e m a ́ t i c a, ~ E s t a t i ́ s t i c a ~ e ~ F i ́ s i c a ~}$ \\ Universidade Federal do Rio Grande \\ Campus Carreiros. Av. Itália s/n Km 8 \\ CEP 96201-900. Rio Grande, RS, Brasil \\ wilianmarques47@gmail.com \\ Received: July 15, 2017 \\ Revised: August 09, 2017 \\ Accepted: December 26, 2017
}

\section{ABSTRACT}

Global forecast models have been widely used worldwide; however, they lack ability to prescribe high quality local data. In this paper, an assembly of oceanographic (RTOFS) and atmospheric (GFS) global data base are used to set up a nested forecast system. The approach proposed relies on the usage of python and FORTRAN scripts to download and assemble global metocean data, in addition to interpolate it towards the study area numerical grid as boundary conditions. Therefore, the TELEMAC-3D hydrodynamic model is automatically initiated in order to provide the regional forecast for the Southern Brazilian Continental Shelf. Results shows that the methodology proposed represent properly the flow dynamics inside the Patos Lagoon and also in the Tramandaí beach, with low/high frequency dynamic effects and influences being reported.

\section{NOMENCLATURE}

GFS Global Forecast System

NLR Naval Research Laboratory

GODAE Global Ocean Data Assimilation Experiment

TR Tramandaí

RG Rio Grande

open TELEMAC-MASCARET

mathematical solvers

TELEMAC-3d Hydrodynamic 3D model

RTOFS Real Time Ocean Forecast System

NOAA National Oceanic and Atmospheric Administration

HYCOM HYbrid Coordinates Ocean Model

NCODA North-American Navy assimilation system

UTM Universal Transverse Mercator coordinate system

openDAP Open-source Project for a Network Data Access Protocol

netCDF4 Network Common Data Form
NOMADS NOAA Operational Model Archive and Distribution System

OTPS Oregon State University Global Tidal Solutions

STJ Subtropical Jet

NE North-east

SO South-west

STCZ Subtropical Convergence Zone

Suite of ENSO El Niño-Southern Oscillation

SSH Sea surface height

\section{INTRODUCTION}

Climate forecast numerical models produced by combining models with observations provide mathematical descriptions of the recent climate. Global forecasting systems deliver estimates for all locations on earth, and they span a long period that can extend back by decades or more. Forecasting involves the collection, preparation, and assessment of climate observations, ranging from early in-situ surface observations made by meteorological 
observers to modern high-resolution satellite data sets (Kalnay and Kanamitsu, 1996).

Computational advances and geostationary satellites enhanced the quality of atmospheric forecasts. The Global Forecast System (GFS) is the most used atmospheric forecasting model in the world, among several other models that are currently operational (Lynch, 2008).

The development of oceanographic forecasting systems occurred considerably later than atmospheric systems. The earlier operational oceanographic forecasts were developed by the Naval Research Laboratory (NLR) and date back to late 1990's (Kalnay and Kanamitsu, 1996; Smedstad et al., 2003). The Global Ocean Data Assimilation Experiment (GODAE) directly invested and propelled the development of oceanic global forecasting systems and oceanographic data assimilation by investing (Dombrowsky et al., 2008).

The study area (figure 1) is located in the eastern margin of South America, between $28^{\circ} \mathrm{S}$ and $35^{\circ} \mathrm{S}$, including the Rio Grande do Sul and southern Santa Catarina coasts, and the Patos Lagoon. The region dynamics is inserted within the Southern Brazilian Continental Shelf.

The PCSB has a wide continental shelf influenced by the Brazilian Current and the Malvinas Current. It is strongly marked by the presence of tropical, subtropical and polar water masses, with distributions that change in different timescales (Palma et al., 2004a,b, 2008). Additionally, a densitydriven circulation transports waters of the La Plata river plume and colder, nutrient-richer waters, towards the south of Brazil (Soares et al., 2007a,b).

Locally, interactions between the Patos Lagoon and La Plata river plumes control the circulation of the inner continental shelf, affecting the local biological production (Marques et al., 2009, 2010a,b; Seeliger and Odebrecht, 2010).
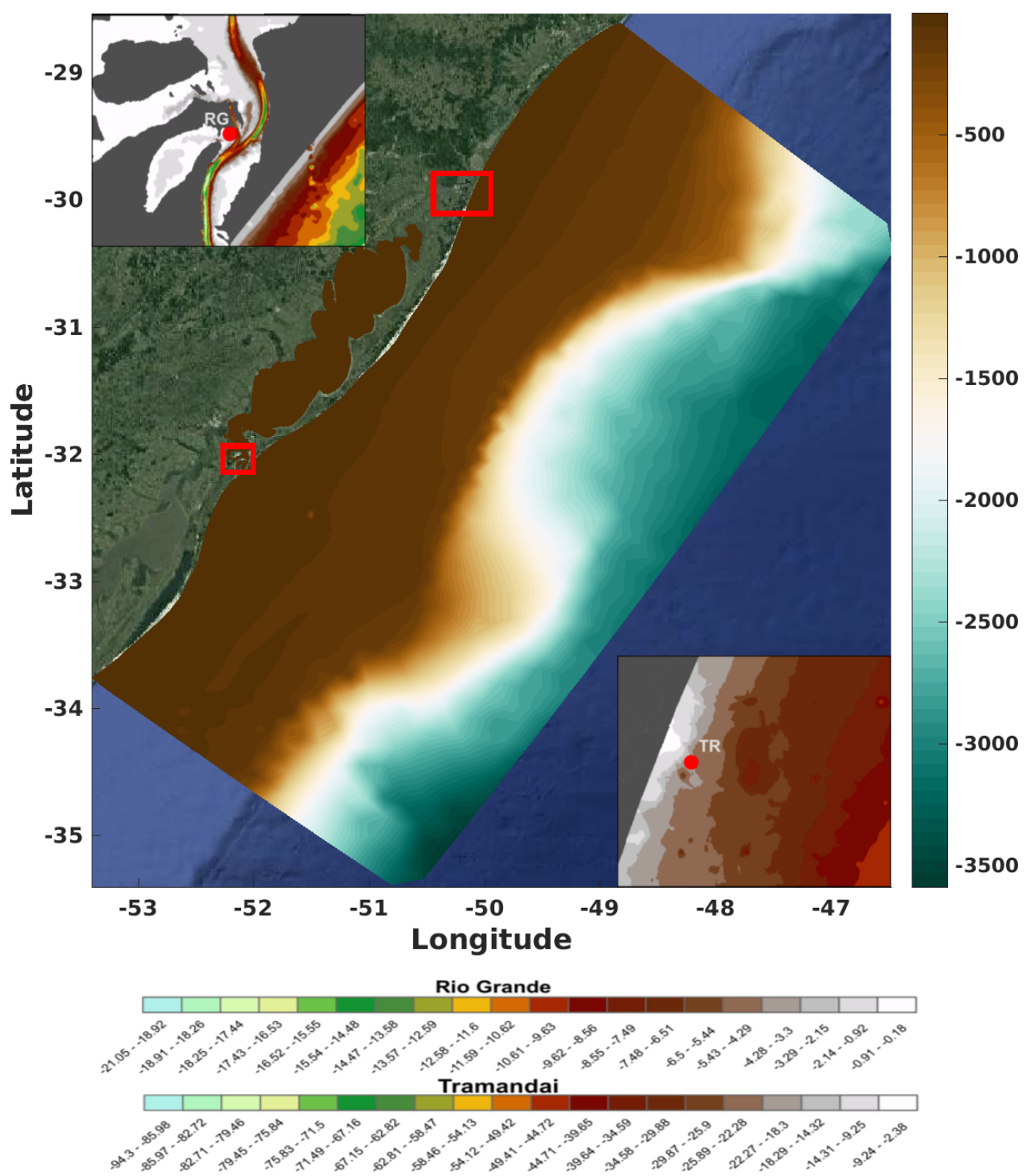

Figure 1. Study area. Red dots (TR, RG) represent the points where the time series were taken. The regions of Rio Grande Harbor and Tramandaí are shown in details. 


\section{METHODOLOGY}

Hydrodynamic processes were simulated using the tridimensional hydrodynamic model TELEMAC-3D, developed within the frame of the open TELEMAC- MASCARET consortium. TELEMAC-3D solves the Navier-Stokes equation considering the local variations on the fluid free surface, neglecting density variations in the mass conservation equation, and using the Boussinesq approximation to solve the momentum equations Hervouet (2007).

The numerical domain was discretized using the finite-element technique and equally-spaced vertical sigma levels, resulting in a numerical mesh with higher spatial resolution at regions of interest. This discretization scheme avoids the costs of mesh nesting, such as discontinuities and higher computational cost (Neta, 1992). A complete description of the TELEMAC-3D model and the finite-element technique are provided by Hervouet (2007).

The Global Forecast System - GFS carried out by NOAA (Kanamitsu et al., 1991) provided meteorological data required for hydrodynamic forecasting. The GFS model is one of the production models used by the National Centers for Environmental Prediction - NCEP to perform global atmospheric forecasts. The model formulation is based on traditional conservation laws of momentum, energy and mixing, solved for a Gaussian grid with $28 \mathrm{~km}$ of horizontal spatial resolution. Wind, temperature and precipitation fields' forecasts can reach up to fifteen days with acceptable reliability (Stopa and Cheung, 2014).

Oceanographic data were provided by the Real Time Ocean Forecast System - RTOFS, a project ran by NOAA (Bleck, 2002). It consists of an operational implementation of the HYbrid Coordinates Ocean Model - HYCOM with a $0.03125^{\circ}$ spatial resolution and 34 vertical hybrid levels (Chassignet et al., 2006). The RTOFS can adequately solve mesoscale oceanic vortex and broader scale structures, such as western boundary currents.

RTOFS is run once a day, providing two days of nowcast and six days of forecast. The initial conditions are set using tridimensional fields of temperature, salinity and sea level. The data is provided by the North-American Navy assimilation system NCODA (Cummings, 2005).

\section{THE FORECASTING SYSTEM}

The forecasting system structure is schematic according to figure 2 . The forecast starts with three scripts that download the data used to set the initial and boundary conditions. A CRON job automatically initializes the scripts every day at $20 \mathrm{Z}$ (UTM time). The RUN_OPERATION calls the scripts TELEMAC INIT and TELEMAC_ATM, and the Steering file function, either manually or automatically (if configured to be called by the CRON job). At this point, all the parameters and files are configured, so the code is compiled, and the FORECAST.exec is executed and starts the post-processing of the results.

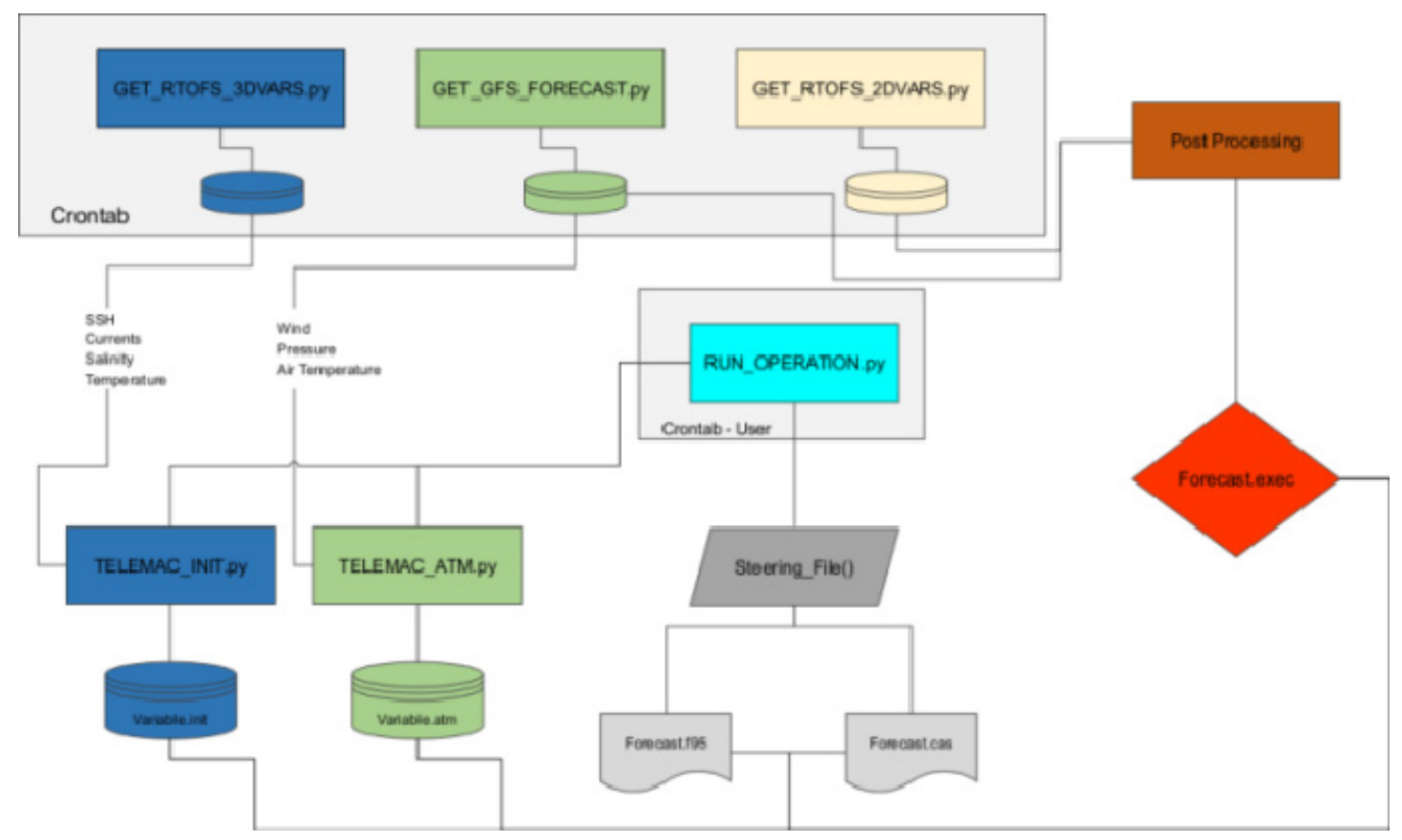

Figure 2. Operational forecast structure. From above to bottom: data acquisition, initial and boundary conditions creation, update of FORTRAN parameterization file, compile, execution of the code and post processing. 

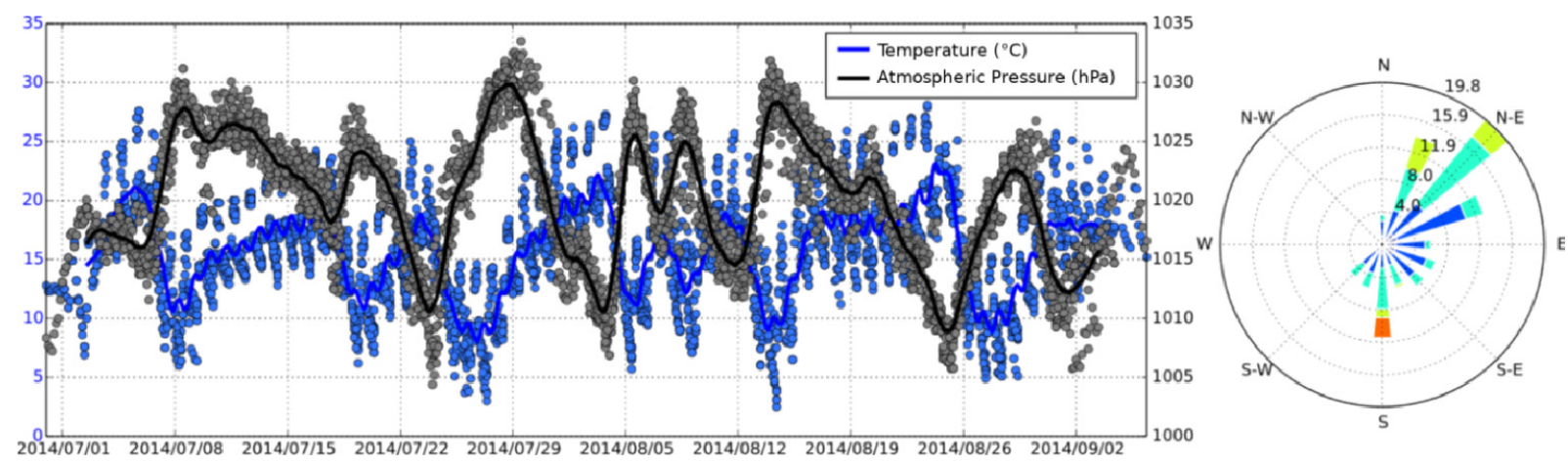

Figure 3. Atmospheric pressure, air temperature, intensity and wind direction in Tramandaí during the studied period. Gray and blue points represent all observed values, while the black and blue curve stands for the best fit for the forecast variability. The wind is represented by the wind rose on the right.

First, the GET_GFS_FORECAST access the NOMADS server using openDAP protocols and downloads the air temperature, atmospheric pressure at the sea level and the components of wind velocity at $10 \mathrm{~m}$ of height above the sea level. The data is written in the netCDF4 format to the local disk. The script builds the atmospheric database and also generates graphical visualizations of the air temperature, pressure and wind fields. The data has $3 \mathrm{~h}$ of temporal resolution and 0.5 degrees of spatial resolution, covering the region comprised between $-40^{\circ} \mathrm{S}$ and $-10^{\circ} \mathrm{S}$; and -60 to $30^{\circ} \mathrm{W}$.

The GET_RTOFS_2DVARS script downloads the bidimensional variables of the RTOFS, with a temporal resolution of $3 \mathrm{~h}$, a spatial resolution of 1/32 degrees, covering the same area of the atmospheric database. These variables are not directly used for forecasting. However, maps of sea surface temperature and surface currents are drawn to examine the integrity of the data. The access to the NOMADS servers is performed using the openDAP protocols.

Finally, the GET_RTOFS_3DVARS script is started and access the oceanographic data that will be used to run the forecast, i.e., tridimensional fields of temperature, salinity, and currents, with a temporal resolution of $24 \mathrm{~h}$ and spatial resolution of $1 / 32$ degrees. The data is written locally using the netCDF4 format. Once all the data is downloaded, and their integrity is verified, the RUN_OPERATION starts to run.

The data prepared by the TELEMAC_INIT and TELEMAC_ATM scripts are accessed by the TELEMAC-3D when it starts running. The model internally interpolates the data for each time step, creating the boundary conditions. The model returns an error message and stops the forecasting if any of the data files is corrupted or contains less data than expected.

The RUN_OPERATION script is called when the simulations are finished, and cleans the temporary files, moves the results to their final destination, sends an email informing the end of the operation and calls the post-processing scripts.

\section{SUPERFICIAL AND BOUNDARY CONDITIONS FOR TELEMAC-3D}

The hydrodynamic model uses temperature, salinity and velocity tridimensional data as initial conditions. Tridimensional RTOFS data are accessed and linearly interpolated to the unstructured numerical domain. The tridimensional

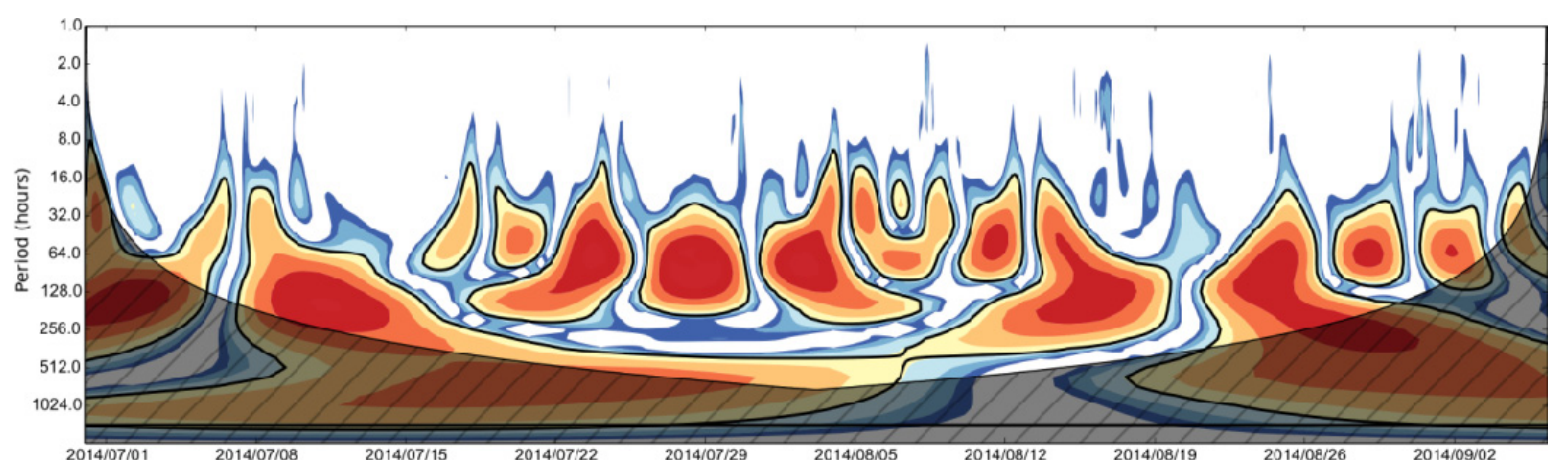

Figure 4. Wavelet for the atmospheric pressure curve (presented in figure 3) in Tramandaí. Local power spectra calculated with Morlet Wavelet $(\mathrm{m}=6)$; Thick contour lines enclose regions of greater than $95 \%$ confidence for a red-noise process with a lag-1 coefficient of 0.95 . Cross-hatched regions indicate the cone of influence where edge effects become important. 


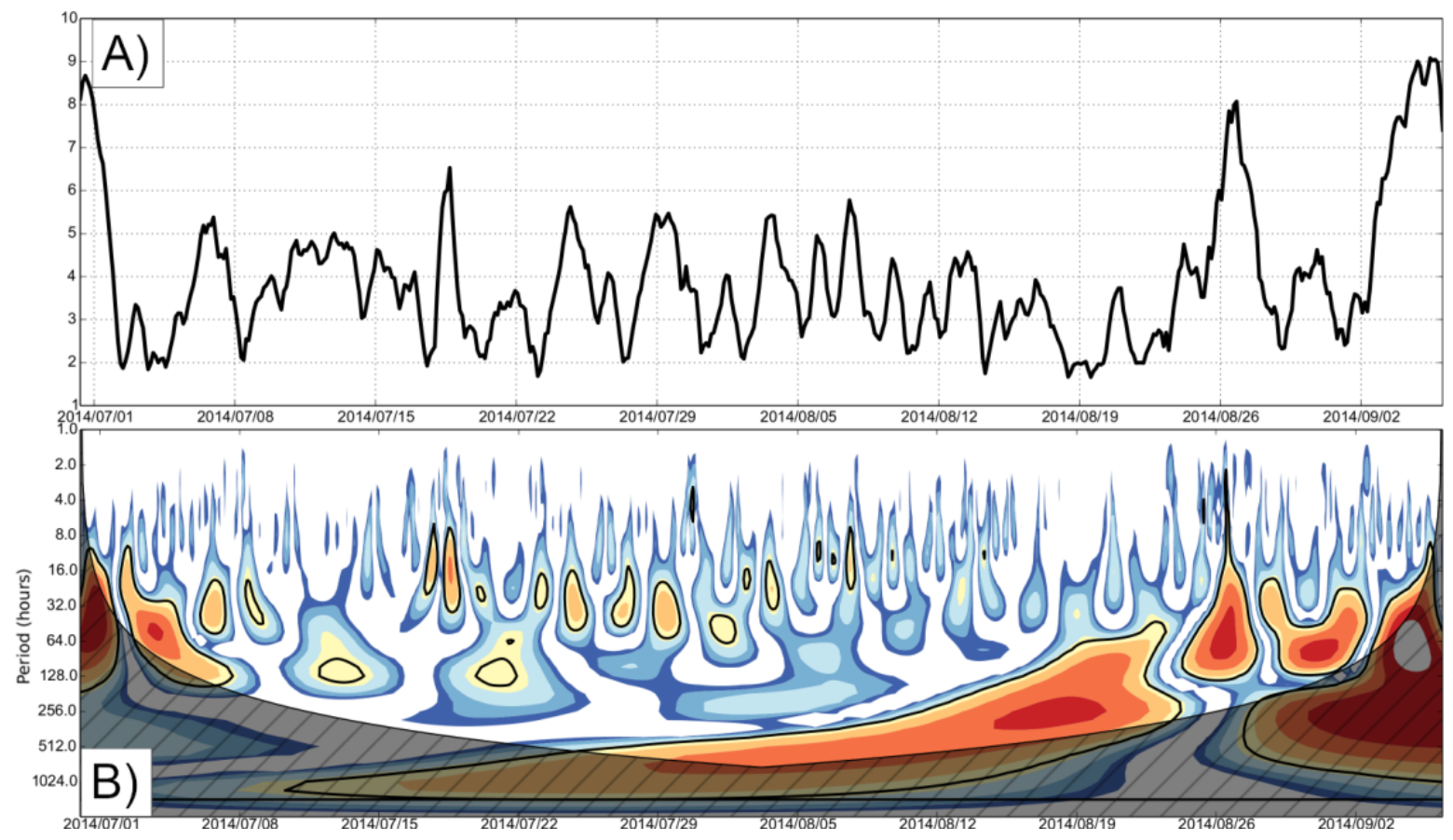

Figure 5. Wavelet for the wind intensity in Tramandaí. a) Variation time series for the wind intensity for the entire simulated period. b) Local power spectra calculated with Mexican Hat Wavelet $(\mathrm{m}=2)$; Thick contour lines enclose regions of greater than $95 \%$ confidence for a red-noise process with a lag- 1 coefficient of 0.95 .

Cross-hatched regions indicate the cone of influence where edge effects become important.

structure of the sigma levels is rebuilt, and then the RTOFS planes that most coincide with the TELEMAC-3D planes are determined and assigned as initial conditions. The tides were imposed directly on TELEMAC-3D (Pham and Lyard, 2012), with the results from the OTPS Global Tidal Solutions (Edgbert and Erofeeva, 2002) developed by the Oregon State University.

A similar procedure is executed to incorporate the superficial forcing (wind fields, atmospheric pressure, and air temperature). RTOFS regularly gridded data are interpolated to the unstructured grid; however, the process evolves in time, so data files containing superficial conditions are generated every $3 h$.

River discharge is a major forcing of the Patos
Lagoon circulation and formation of its plume formation (Marques et al., 2009, 2010b,a). Tough, real-time discharge measurements are not available, neither a hydrological forecasting system. In this work, we used average discharges of the JacuíTaquari system (1000 ms-3), Camaquã (700 ms-3) and São Gonçalo (600 ms-3) rivers obtained by Marques (2012) to force liquid boundaries.

\section{RESULTS AND DISCUSSION}

\section{Atmosphere Forecast}

Figure 3 shows the variability of air temperature, atmospheric pressure and wind intensity on TR. Gray (blue) dots represent all

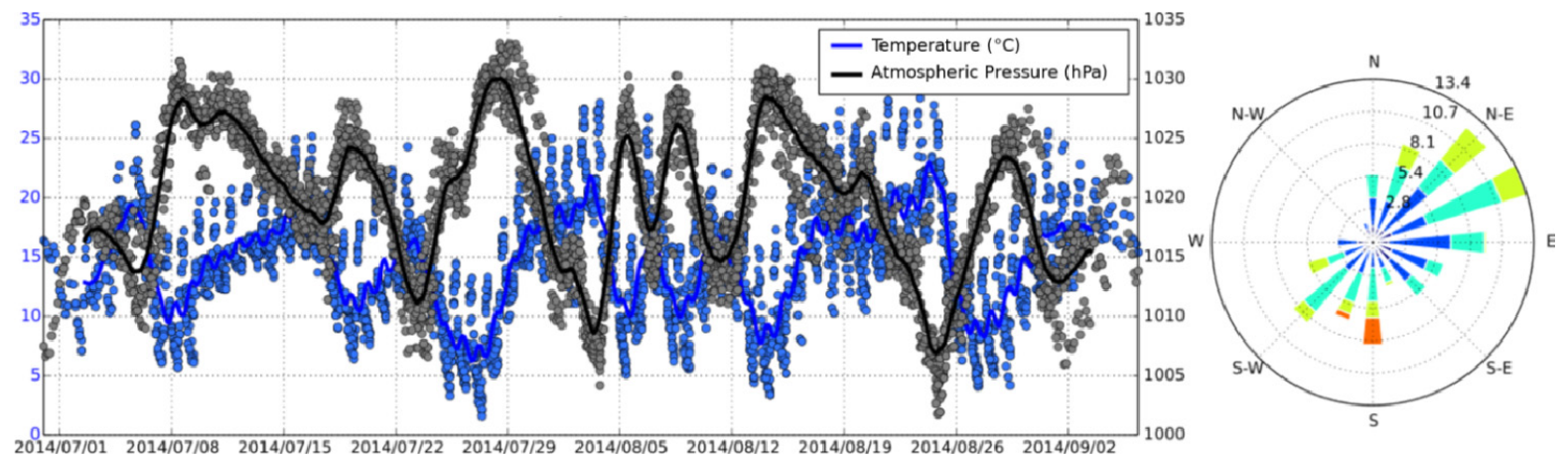

Figure 6. Atmospheric pressure, air temperature, intensity and wind direction in Rio Grande during the studied period. Gray and blue points represent all observed values, while the black and blue curve stands for the best fit for the forecast variability. The wind is represented by the wind rose on the right. 


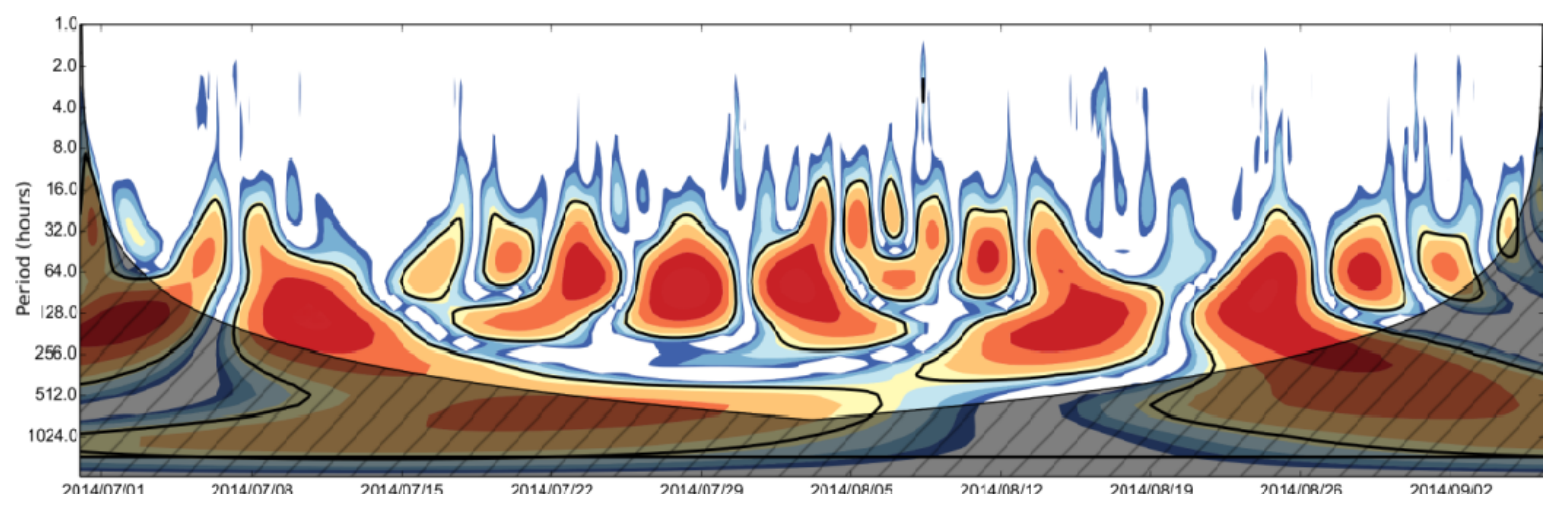

Figure 7. Wavelet for the atmospheric pressure curve (presented in figure 6) in Rio Grande. Local power spectra calculated with Morlet Wavelet $(\mathrm{m}=6)$; Thick contour lines enclose regions of greater than $95 \%$ confidence for a red-noise process with a lag-1 coefficient of 0.95 . Cross-hatched regions indicate the cone of influence where edge effects become important.

pressure (temperature) values obtained by each forecast, and the black (blue) line represents the curve that best fits the forecast variability, obtained by averaging the values with a $24 \mathrm{~h}$ running window curve that best fits the forecast variability, obtained by averaging the values with a $24 \mathrm{~h}$ running window.

Alternated low and high pressures (temperatures) are associated with the passage of cold fronts and to the formation of the South Atlantic High-Pressure Center, respectively. At least three low-pressure events occurred during the simulated period, followed by a decrease of air temperature and subsequently by high pressure and warmer temperature.

Three main meteorological systems control the atmospheric dynamics in South America. The South Atlantic High-Pressure Center and the Polar Mobile Anticyclone are high-pressure zones, and the region comprised between both is a depression where winds from both systems converge (Gan, 1992). Such convergence creates the cold front cyclonic circulation, generally associated with the Subtropical Convergence Zone and the BrazilMalvinas confluence (dal Piva et al., 2008).

Figures 4 and 5 shows wavelet analyses of atmospheric pressure and wind intensity, respectively, in Tramandaí. The results within the 95\% significance level indicate that the atmospheric pressure has energetic cycles with periodicities of 32 to 256 hours. Such cycles reflect the passage of frontal systems with southwesterly winds (low pressure) and the restoration of the northeasterly winds (high pressure).

Stringari and Marques (2014) observed synoptic systems with the same time scale for the Tramandaí region during the summer of 2012, analyzing the cross-correlation between currents intensity and wind intensity. Wavelet analysis of wind intensity (figure 5 b.) has significant cycles with shorter duration ( 8 to 32 hours) which may correspond to the variability associated with marine/terrestrial breeze.

Figure 6 presents the atmospheric variables on RG. The results are similar to those shown in figure 3 , with a remarkable alternation of low and highpressure systems in response to the passage of cold fronts and the restoration of the South Atlantic high-pressure system.

However, the temperatures are lower in $\mathrm{RG}$ when compared to Tramandaí, which is probably due to the latitudinal difference among both locations. The winds in RG are distributed between the $\mathrm{N}$ and $\mathrm{W}$ quadrants, whereas in Tramandaí the winds mostly align with the NE-SO axis. The Subtropical Jet (STJ) position is an important factor determining the atmospheric conditions observed in Rio Grande and Tramandaí during the study period. Synoptic maps produced during the forecasts indicate that the STJ was displaced southwards to its normal position, which implies that polar frontal systems reaching the region are deflected towards the ocean. This blockage causes trapping of the winds from SW in the southern portion of the continent and causes the differences observed between RG and Tramandaí.

According to Grimm (2003), during ENSO events, the subsidence of the air in the Walker Cells is weakened by the warming of the equatorial Pacific waters. It allows the formation of jets at the higher layers of the atmosphere, bringing dry air to the Northeast and Southeast's regions of Brazil and causing above average precipitation in Southern Brazil.

Part of this dry air mass originated in the equatorial Pacific ocean feeds the Subtropical Convergence Zone (STCZ) at $30{ }^{\circ} \mathrm{S}$, increasing the blockage of frontal systems. The Walker Cells weakening during ENSO events intensifies the STJ and the STCZ, which modifies the position of the South Atlantic High- Pressure System and then the direction and intensity of the winds observed in the state of Rio Grande do Sul coast. Guim (2010) analyzed wind intensity and direction data from 


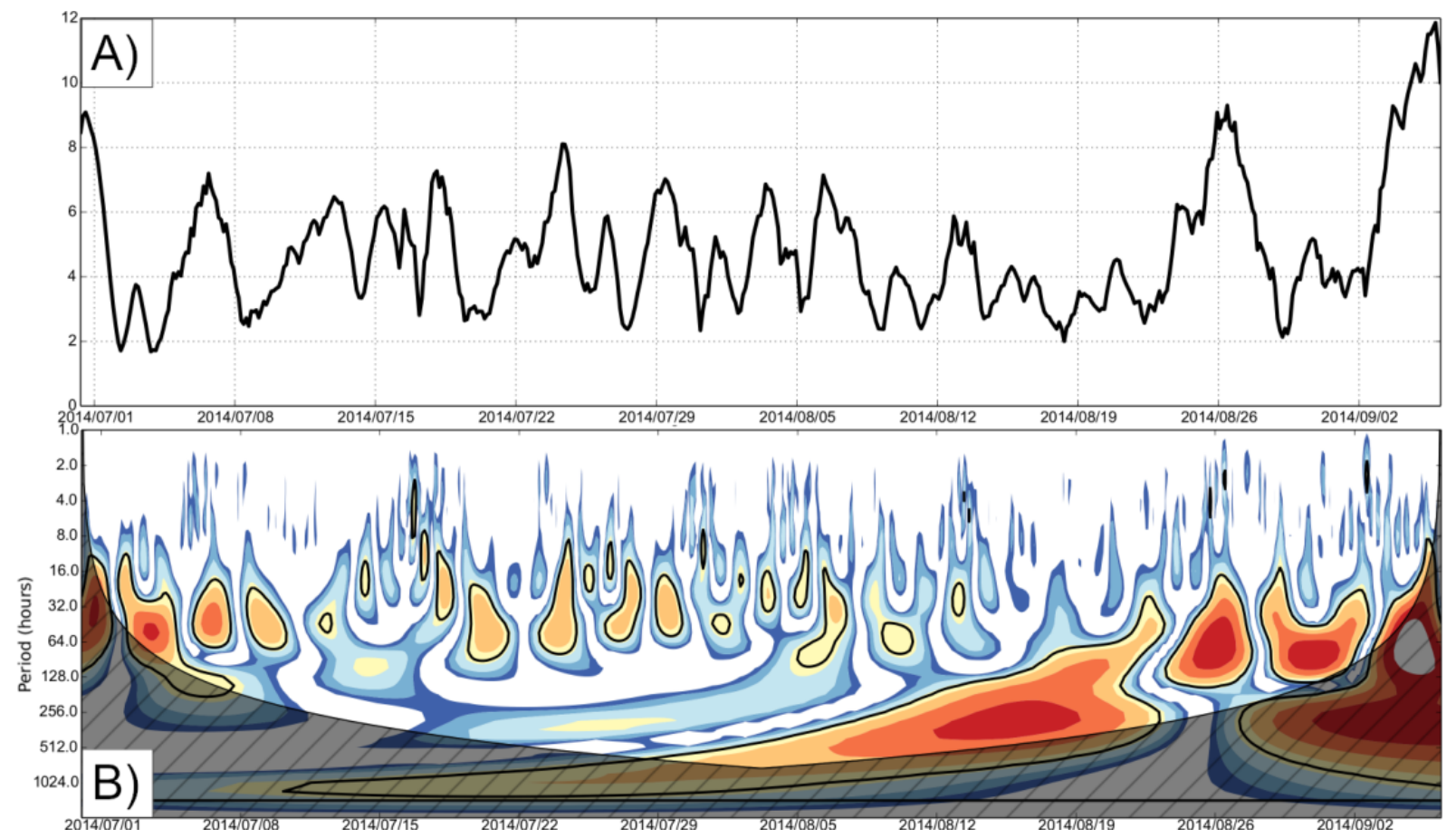

Figure 8. Wavelet for the wind intensity in Rio Grande. a) Variation time series for the wind intensity for the entire simulated period. b) Local power spectra calculated with Mexican Hat Wavelet $(\mathrm{m}=2)$; Thick contour lines enclose regions of greater than $95 \%$ confidence for a red-noise process with a lag-1 coefficient of 0.95 . Cross-hatched regions indicate the cone of influence where edge effects become important.
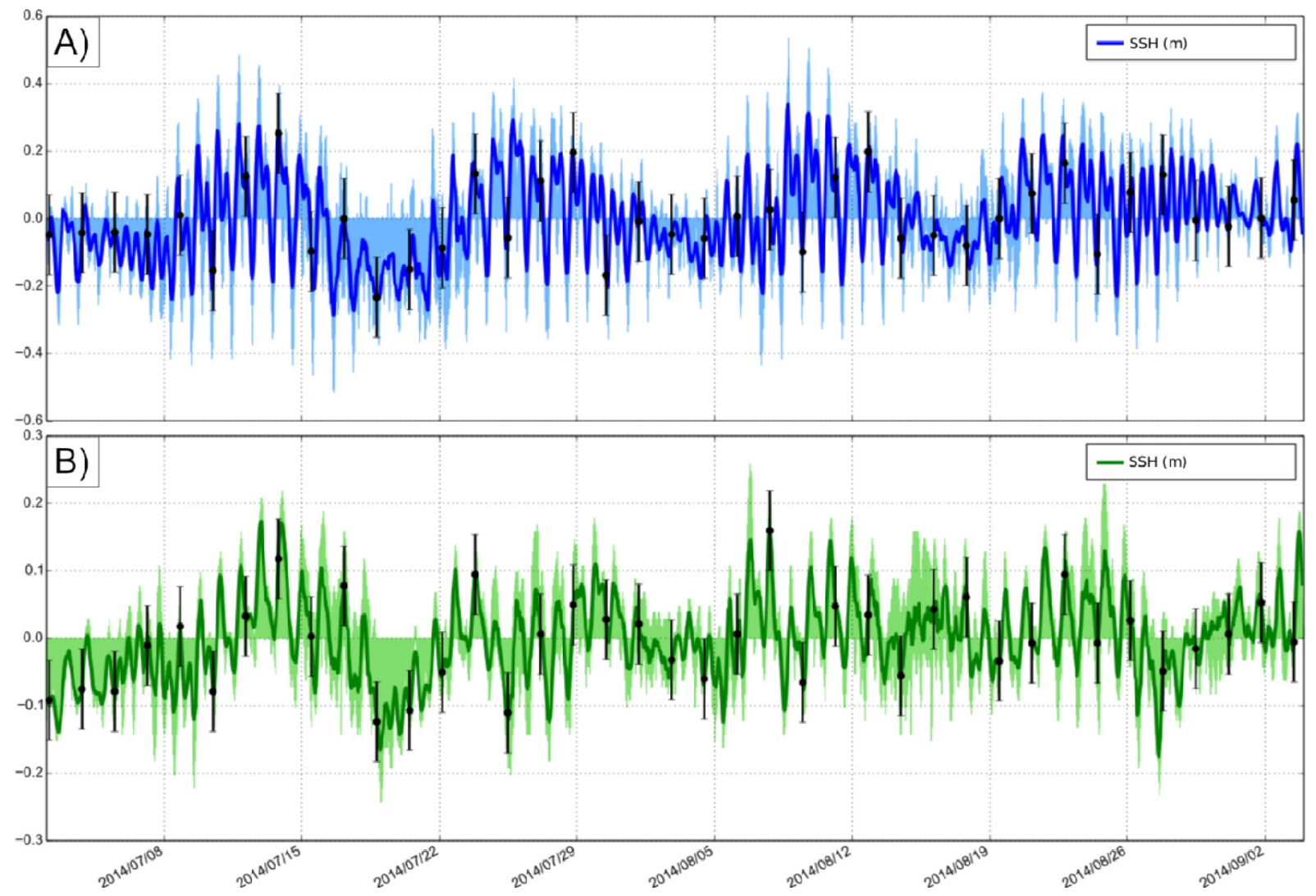

Figure 9. Sea surface height (SSH) high frequency variation for Tramandaí (a) and Rio Grande (b). The light blue (green) envelop indicates the variability of the results in all simulations performed while the dark blue (green) line stands for the best fit of observed values. The error bars indicates one standard deviation of error. 
2006 to 2008 and found the same blockage effect during ENSO events.

Figures 7 and 8 shows wavelet analyses of atmospheric pressure and wind intensity on RG. The Mexican Hat wavelet, with $\mathrm{m}=2$, showed the best adjustment for the series. The observed pattern is similar to Tramandaí, where the atmospheric pressure is described by a synoptic variability controlled by the passage of frontal systems, whereas the winds capture shorter cycles.

\section{Hydrodynamic Forecast}

The analysis process is similar to the one applied to atmospheric variables. All forecasts were plotted continuously, superimposing different values for the same day. This variability is represented in the figures by dashed envelopes, and a curve is adjusted to represent the desired frequency by applying of a moving average. To represent high (low) frequencies, the curves were adjusted for $3 \mathrm{~h}$ (96h). The standard deviation of each day is represented by vertical bars. Blue colors represent Tramandaí data, and Green colors represent Rio Grande.

Figures 9a. and 9b. shows the high-frequency results of sea surface height (SSH), respectively on TR and RG. The tidal variability is observed in both locations, with a daily cycle and a syzygyquadrature cycle.

Both series are disturbed by less regular cycles, probably associated with atmospheric forcing. The amplitude variability of Rio Grande is about half the values observed for Tramandaí. The difference is due to the attenuation of tides imposed by the Patos Lagoon estuary, which restricts the tidal influence in the Patos Lagoon (Fernandes et al., 2004).

The forecasts result variability reflects the model sensitivity to the initial conditions. However, the adjusted series with their standard deviations are always inside or very close to the total variability envelope, indicating that the model forecasts are plausible conditions. If the standard deviations of the adjusted series had considerably diverged from the total variability envelope, it would indicate that consecutive forecasts had presented entirely divergent results.

Figures 10a. and 10b. show the low-frequency (subtidal) results of sea level, respectively on TR and RG. The time series were obtained by applying a $96 \mathrm{~h}$ running mean on the forecasting results. Two syzygy-quadrature cycles and perturbations caused by meteorological systems are distinctively observed in Tramandaí. However, the tidal cycles are not easily observed in Rio Grande due to its location inside the Patos Lagoon estuary.

According to Kjerfve (1986), the surface flow of choked lagoons is predominantly ruled by the wind, because the complex morphology increases the relative effect of the shear stress and reduces the amplitude of tidal waves that propagate towards the estuary (Woo and Yoon, 2011). Moller et al. (2001) studied the influence of local and remote winds, observing sea level heights similar to the present work. Many other studies corroborate the sea level results found (Marques et al., 2010b, 2009; Fernandes et al., 2002, 2004; Moller et al., 2001, 1996).

Analysis of sea level amplitude variability directly shows that the model's performance was satisfactory. However, it does not reveal which processes cause the variability. Hence, we performed wavelet transforms for Rio Grande and Tramandaí to separate those effects.

The global wavelet spectrum (figure 11) shows the separation of processes in a lowfrequency cycle (temporal scale of days) and a high-frequency cycle (temporal scale of hours). The low-frequency cycle represents the passage of frontal meteorological systems and the subsequent restoration of the South Atlantic Anticyclone, similar to the findings of Stringari and Marques (2014) for the Summer of 2012. The most energetic processes of high-frequency (figure 11 , between 8 and 36 hours) have periodicities corresponding to the daily tidal oscillations.

On the other hand, it is not possible to observe the separation of processes occurring in cycles of low and high frequencies in Rio Grande (figure 12). High-frequency cycles are not as remarkable as they are in Tramandaí, due to the attenuation of the tidal influence imposed by the narrow channel that connects the estuary to the continental shelf (Fernandes et al., 2004). Moreover, the local and remote effects of the wind acting over the coastal zone and the lagoon body may be masked in the local energy spectrum.

Moller et al. (2001) observed that winds from the NE quadrant could block the entrance of tidal waves towards the estuary because the winds directly oppose the tidal propagation. Moller et al. (2001) and (Fernandes et al., 2004) observed that additionally to the attenuation of tidal oscillations, subtidal cycles are filtered in the mouth.

\section{CONCLUSIONS}

The present work is focused on the utilization of global forecasting systems together with the use of the TELEMAC-3D to create an operational system for forecasting the hydrodynamics of the Southern Brazilian Continental Shelf. According to the proposed objective, the main results are summarized as follows:

- The system was operational during the period comprised between 01/07/2014 to $31 / 08 / 2014$, resulting in a database with $800 \mathrm{~GB}$;

- The results obtained during the simulation period were discussed regarding the quality of the generated forecasts; 

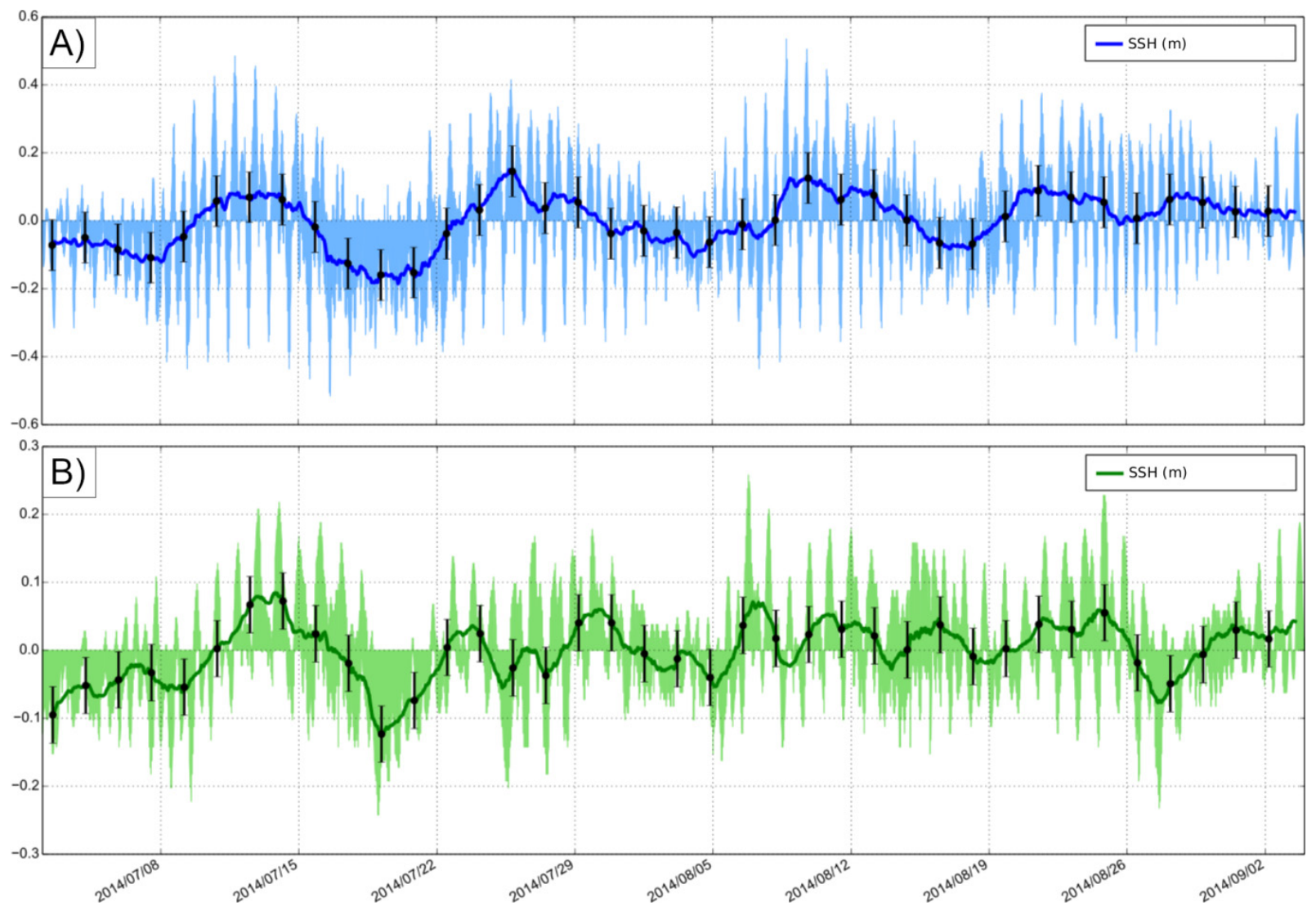

Figure10. Sea surface height (SSH) low frequency variation for Tramandaí (a) and Rio Grande (b). The light blue (green) envelop indicates the variability of the results in all simulations performed while the dark blue (green) line stands for the best fit of observed values. The error bars indicates one standard deviation of error.

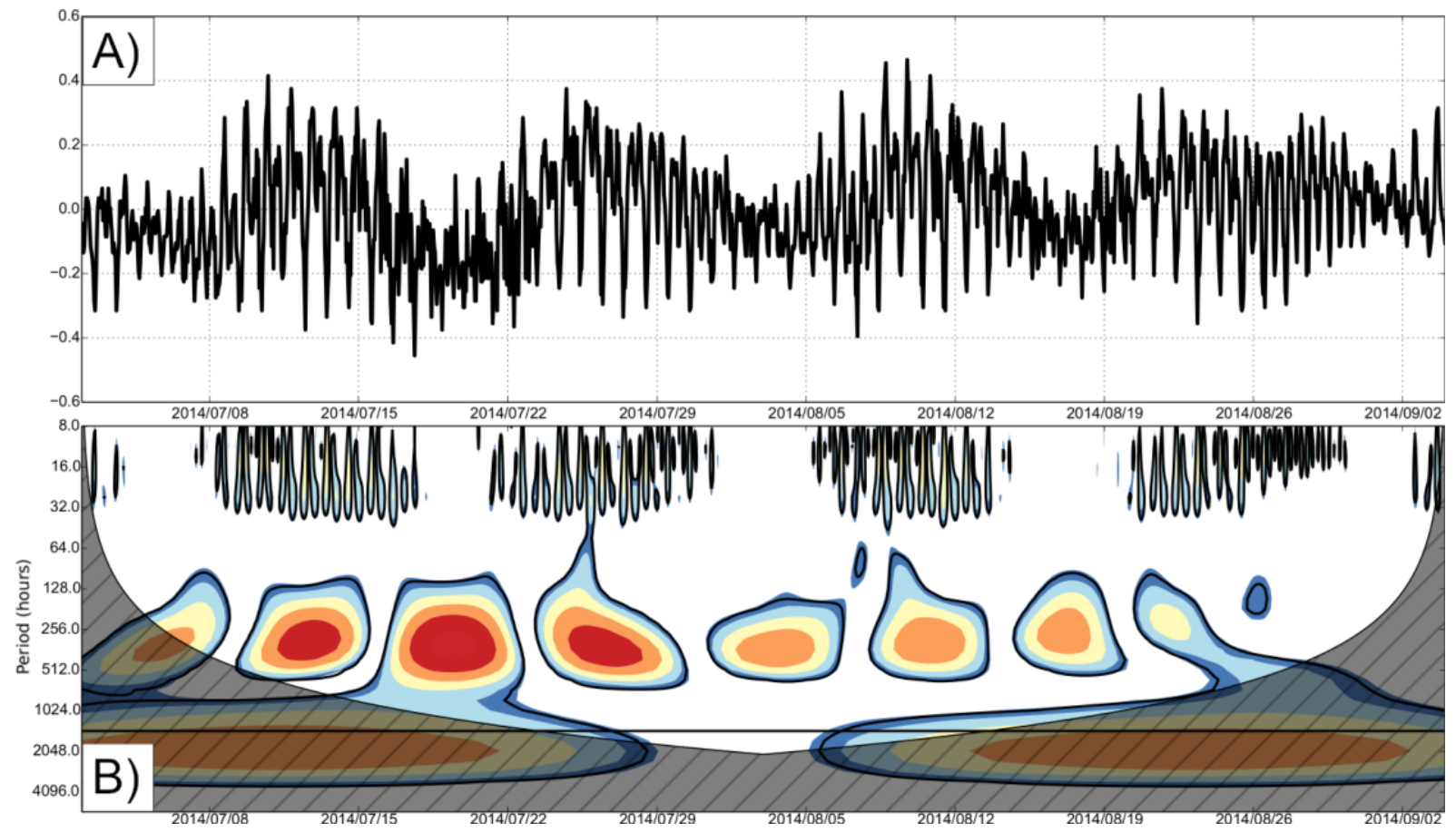

Figure 11. Wavelet analysis for sea surface height in Tramandaí. a) Time series of SSH for the entire simulated period. b) Local power spectra calculated with Mexican Hat Wavelet $(\mathrm{m}=2)$; Thick contour lines enclose regions of greater than $95 \%$ confidence for a red-noise process with a lag-1 coefficient of 0.95 . Cross-hatched regions indicate the cone of influence where edge effects become important. 
- Analysis of atmospheric variables indicate that processes occur in two different time scale: a low-frequency time scale represented by the passage of frontal meteorological systems over the region and another a high- frequency timescale, probably related to marine breeze circulation;

- The sea level variations were used as model performance diagnose variable. Low-frequency cycles are related to syzygy-quadrature tidal cycles, and high-frequency cycles may reflect either daily tidal cycles, inertial oscillations, and barotropic circulation;

- Future works will be focused on coupling the hydrodynamic forecast model to operational modules of local and regional importance, to analyze oil spills, wastewater dispersion, and ship dynamics.

\section{ACKNOWLEDGEMENTS}

The authors are grateful to the Conselho Nacional de Desenvolvimento Científico e Tecnológico (CNPq) under contract 304227/2016-1 and to the Agência Nacional do Petróleo (ANP) regarding the Programa de Recursos Humanos (PRH-27) for the fellowship. To the Coordenação de Aperfeiçoamento de Pessoal de Nível Superior (CAPES) for bursaries related to the Programa Nacional de Pós Doutorado. Further acknowledgements go to the Open TelemacMascaret Consortium for freely distribution of the TELEMAC system making viable this research and finally a special thanks to the Supercomputing Center of the Federal University of Rio Grande do Sul (CESUP-UFRGS) and to the SDumont Supercomputer from the Laboratório Nacional de Computação Científica (LNCC) (SDUMONT2017-C01\#166515) where most of the computational work was carried out.

\section{REFERENCES}

Bleck, R., 2002, An Oceanic General Circulation Model Framed in Hybrid IsopycnicCartesian Coordinates, Ocean Modelling, Vol.4, pp. 55-88.

Chassignet, E. P., Hurburt, H. E., Smedstad, O. M., Halliwell, G. R., Wallcgraft, A. J., Metzger, E. J., Blanton, B. O., Lozano, C., Rao, D. B., Hogan, P. J., and Srinivasan, A., 2006, Generalized Vertical Coordinates for Eddy-Resolving Global and Coastal Ocean Forecasts. Oceanography, Vol. 19, pp. 20-33.

Cummings, J. A., 2005, Operational Multivariate Ocean Data Assimilation, Quarterly Journal of the Royal Meteorological Society, Vol. 131 No. 613, pp. 3583-3604.

dal Piva, E., Moscati, M. C. D. L., and Gan, M. A., 2008, Papel dos Fluxos de Calor Latente e Sensível em Superfície Associado a um Caso de
Ciclogenese na Costa Leste da América do Sul, Revista Brasileira de Meteorologia, Vol. 23, No. 4, pp 450-476. (in Portuguese)

Dombrowsky, E., Bertino, L., Brassington, G., Davidson, F., Hurlburt, H., Kamachi, M., Lee, T., Martin, M., Mei, S., Tonani, M., Environmental, N., Johns, S., Office, M., Marine, N., and Forecast, E., 2008, GODAE Systems in Operation, Oceanography, Vol. 22, No. 3, pp. 80-95.

Edgbert, G. D., and Erofeeva, S. Y., 2002, Efficient Inverse Modeling of Barotropic Ocean Tides, Journal of Atmospheric and Oceanic Technology, Vol. 19, pp. 183-204.

Fernandes, E. H. L., Dyer, K. R., Moller, O. O., and Niencheski, L. F. H., 2002, The Patos Lagoon Hydrodynamics during an El Ni no Event (1998), Vol. 22, pp. 1699-1713.

Fernandes, E. H. L., Mariño Tapia, I., Dyer, K. R., and Möller, O. O., 2004, The Attenuation of Tidal and Subtidal Oscillations in the Patos Lagoon Estuary, Ocean Dynamics, Vol. 54, No. 3-4, pp. 348-359.

Gan, M. A., 1992, Ciclogenese e Ciclones sobre a America do Sul, Doctoral Thesis, Instituto Nacional de Pesquisas Espaciais-INPE, São José dos Campos, SP. (in Portuguese)

Grimm, A. M., 2003, The El Nino Impact on the Summer Monsoon in Brazil: Regional Processes versus Remote Influences, Journal of Climate, Vol. 16, No. 1987 , pp. 263-280.

Guimarães, P. V., 2010, Morfodinâmica do Pós-Praia e Duna Frontal com Auxilio de VideoMonitoramento, Doctoral Thesis, Instituto de Oceanografia-UFRG, Cassino, RS. (in Portuguese)

Hervouet, J. M., 2007, Hydrodynamics of Free Surface Flows: Modelling with the Finite Element Method, Wiley.

Kalnay, E., and Kanamitsu, M., 1996, The NCEP/NCAR 40-Year Reanalysis Project. Technical Report, Bulletin of the American Meteorological Society.

Kanamitsu, K., Alpert, J. C., Campana, K. A., Caplan, P. M., Deaven, D. G., Iredell, M., Katz, B., Pan, H.-L., Sela, J., and White, G. H., 1991, Recent Changes Implemented into the Global Forecast System at NMC, Weather and Forecasting, pp. 435434.

Kjerfve, B., 1986, Comparative Oceanography of Coastal Lagoons, Estuarine Variability, Academic Press, pp. 63-81.

Lynch, P., 2008, The Origins of Computer Weather Prediction and Climate Modeling, Journal of Computational Physics, Vol. 227, No. 7, pp. 3431-3444.

Marques, W. C., 2012, The Temporal Variability of the Freshwater Discharge and Water Levels at the Patos Lagoon, Brazil, International Journal of Geosciences, pp. 758-766.

Marques, W. C., Fernandes, E. H., Monteiro, I. O., and Möller, O. O., 2009, Numerical Modeling 
of the Patos Lagoon Coastal Plume, Brazil, Continental Shelf Research, Vol. 29, No. 3, pp. 556-571.

Marques, W. C., Fernandes, E. H. L., and Moller, O. O., 2010a, Straining and Advection Contributions to the Mixing Process of the Patos Lagoon Coastal Plume, Brazil, Journal of Geophysical Research, Vol. 115. No. C6, pp. 1-23.

Marques, W. C., Fernandes, E. H. L., Moraes, B. C., Möller, O. O., and Malcherek, A., 2010b, Dynamics of the Patos Lagoon Coastal Plume and its Contribution to the Deposition Pattern of the Southern Brazilian Inner Shelf, Journal of Geophysical Research, Vol. 115, No. C10, pp. 1-22.

Moller, O. O., Castaing, P., Salomon, J.-C., and Lazure, P., 2001, The Influence of Local and Non-Local Forcing Effects on the Subtidal Circulation of Patos Lagoon, Estuaries, Vol. 24, No. 2, pp. 297-311.

Moller, O. O., Lorenzzetti, J. A. A., Stech, J., and Mata, M. M., 1996, The Patos Lagoon Summertime Circulation and Dynamics, Continental Shelf Research, Vol., 16, No. 3, pp. 335351.

Neta, B., 1992, Analysis of Finite Elements and Finite Differences for Shallow Water Equations: A Review, Mathematics and Computers in Simulation, Vol. 34, pp. 141-161.

Palma, E. D., Matano, R. P., and Piola, A. R., 2004a, A Numerical Study of the Southwestern Atlantic Shelf Circulation: Barotropic Response to Tidal and Wind Forcing, Journal of Geophysical Research, Vol. 109, No. C8, pp. 1-17.

Palma, E. D., Matano, R. P., and Piola, A. R., 2008, A Numerical Study of the Southwestern Atlantic Shelf Circulation: Stratified Ocean Response to Local and Offshore Forcing, Journal of Geophysical Research, Vol. 113, No. C11010, pp. 1-22.

Palma, E. D., Matano, R. P., Piola, A. R., and Sitz, L. E., 2004b, A Comparison of the Circulation Patterns over the Southwestern Atlantic Shelf Driven by Different Wind Stress Climatologies, Geophysical Research Letters, Vol. 31, No. 24, pp. $1-5$.

Pham, C.-T., and Lyard, F., 2012, Use of Tidal Harmonic Constants Databases to Force Open Boundary Conditions in TELEMAC, in: Bourban, S., Durand, N., and Hervouet, J.-M., editors, XIX TELEMAC-MASCARET User Conference, Oxford, Inglaterra, HR Wallingford, pp. 165-172.

Seeliger, U., and Odebrecht, C., 2010, O Estuário da Lagoa dos Patos: um Século de Transformações, Editora Furg. (in Portuguese)

Smedstad, O. M., Hurlburt, H. E., Metzger, E., Rhodes, R. C., Shriver, J. F., Wallcraft, A. J., and Kara, A., 2003, An Operational Eddy Resolving $1 / 16^{\circ}$ Global Ocean Nowcast/Forecast System, Journal of Marine Systems, Vol. 40-41, pp. 341361.
Soares, I. D., Kourafalou, V., and Lee, T. N., 2007a, Circulation on the Western South Atlantic Continental Shelf: 1. Numerical Process Studies on Buoyancy, Journal of Geophysical Research, Vol. 112, No. C4002, pp. 1-20.

Soares, I. D., Kourafalou, V., and Lee, T. N., 2007b, Circulation on the Western South Atlantic Continental Shelf: 2. Spring and Autumn Realistic Simulations, Journal of Geophysical Research, Vol. 112, No. C4003, pp. 1-18.

Stopa, J. E., and Cheung, K. F., 2014, Intercomparison of Wind and Wave Data from the ECMWF Reanalysis Interim and the NCEP Climate Forecast System Reanalysis, Ocean Modelling, Vol. 75, pp. 65-83.

Stringari, C. E., and Marques, W. C., 2014, Numerical Modeling of Small Scale Processes on the Southern Brazilian Inner Shelf, in: Proceedings of the 17th Physics of Estuaries and Coastal Seas (PECS) Conference, Porto de Galinhas, pp. 17-20.

Woo, S. B., and Yoon, B. I., 2011, The Classification of Estuary and Tidal Propagation Characteristics in the Gyeong-Gi Bay, Journal of Coastal Research, Vol. 64, pp. 1624-1628. 